\title{
Um breve panorama sobre a disciplina de Segurança nos cursos de Sistemas de Informação no Brasil
}

\author{
Matheus de Jesus Cristani, Waldenir Cardoso Alves, \\ Gabriel Fernando Knupp Pereira, Nilson Mori Lazarin
}

\author{
${ }^{1}$ Bacharelado em Sistemas de Informação - Centro Federal de Educação Tecnológica \\ Celso Suckow da Fonseca (Cefet/RJ) - Nova Friburgo, RJ - Brasil \\ \{matheuscristani, waldenir.ca_95, luknupp2012\}@hotmail.com \\ nilson.lazarin@cefet-rj.br
}

\begin{abstract}
The Brazilian law about personal data protection comes into force in 2020. In order to comply with this law, it is essential that technology professionals know information security techniques and concepts. This article aims to present an overview of the emphasis on teaching Information Security in Information Systems Bachelor Degree courses in Brazil, as well as a regional comparison.
\end{abstract}

Resumo. A Lei Geral de Proteção de Dados Pessoais (LGPD) entra em vigor em 2020. Para o cumprimento dessa lei, é essencial que os profissionais de tecnologia conheçam técnicas e conceitos de Segurança da Informação. Este artigo tem como objetivo apresentar um panorama sobre a ênfase no ensino de Segurança da Informação nos cursos de Bacharelado em Sistemas de Informação no Brasil, além de um comparativo regional.

\section{Introdução}

Mais de 2 exabytes de dados são gerados e armazenados diariamente no mundo todo e a tendência é que a tecnologia se torne cada vez mais presente e importante na vida de todos [Marr 2018]. Esse avanço tecnológico traz consigo um problema: o aumento no número de ataques cibernéticos. No Brasil, a situação é bastante preocupante, pois, de acordo com um relatório da Norton Cyber Security, o país passou a ser o segundo no ranking com maior número de casos de crimes cibernéticos, afetando cerca de 62 milhões de pessoas e causando um prejuízo de US\$ 22 bilhões [Symantec Corporation 2017]. Diante deste cenário, no Brasil foi aprovada a LGPD, uma lei que define, entre muitos outros itens, que as atividades de tratamento de dados pessoais devem observar o princípio de segurança, através da utilização de medidas técnicas e administrativas para proteger os dados pessoais de acessos não autorizados e de situações acidentais ou ilícitas de destruição, perda, alteração, comunicação ou difusão [BRASIL 2018].

Segurança da Informação é "a proteção contra o uso ou acesso não autorizado à informação e preservação da disponibilidade, integridade e confidencialidade desta mesma informação" [Morris and Thompson 1979]. Para atender a esta demanda, se faz mister que profissionais responsáveis por sistemas de software conheçam técnicas e práticas de Segurança de Sistemas de Informação (SSI). Sendo assim, é essencial que os cursos superiores preparem seus alunos para este cenário. O objetivo deste artigo é analisar a ênfase em SSI nos cursos de Bacharelado em Sistemas de Informação (BSI) de cada região do Brasil e as aptidões dos alunos. 


\section{Trabalhos relacionados}

Em [Albuquerque et al. 2014] são analisados Projetos Pedagógicos de Cursos (PPC) de Instituições de Ensino Superior (IES) de prestígio comparando os PPCs oferecidos por estas e o PPC proposto pela Sociedade Brasileira de Computação (SBC) e conclui que as matrizes curriculares dos cursos de BSI no Brasil diferem largamente das diretrizes definidas pela SBC, tendo pouca ênfase em disciplinas relacionadas à formação específica na área de SI.

O trabalho de [Costa et al. 2018] apresenta um estudo do nível de conhecimento sobre SSI de desenvolvedores que estão no mercado de trabalho. Como resultado, o trabalho identificou que grande parte dos profissionais da área não considera que a formação acadêmica fornece uma preparação adequada para lidar com SSI, além de identificar que para certos tipos de ataques comuns como Buffer Overflow e Credential Stuffing a maioria dos desenvolvedores tem dificuldade em corrigir estas vulnerabilidades adequadamente.

Este trabalho diferentemente dos acima citados, apresenta uma pesquisa curricular e um questionário de avaliação, buscando relacionar a carga horária disponibilizada com o desempenho obtido, separado por região e especificamente realizada com graduandos e recém Bacharéis em Sistemas de Informação.

\section{Metodologia}

A pesquisa sobre a ênfase dos cursos e o nível de conhecimento dos alunos em SSI foi dividida em três etapas: Analise curricular dos cursos de Sistemas de Informação; Construção e aplicação de questionário de avaliação; Análise de dados: Desempenho X Ênfase.

1. Inicialmente foi realizada uma pesquisa na grade de matérias de todos os cursos de Bacharelado em Sistemas de Informação oferecidos no Brasil. Buscando identificar o percentual de cursos que oferecem matérias ligadas à SSI e a média de horas-aula oferecida.

No portal e-MEC, foram filtrados todos os cursos bacharelados de Sistemas de Informação ativos. Com os dados obtidos, foram realizadas pesquisas nos sites das Instituições de Ensino, a fim de obter a grade destes cursos.

Uma vez encontrada a grade, eram listadas as matérias relacionadas à SSI e contabilizadas as hora-aula destinadas.

2. Em seguida, produziu-se um questionário ${ }^{1}$ com o objetivo de avaliar o nível de conhecimento de SSI dos graduados e graduandos de BSI. Foram elaboradas 10 questões sobre: Segurança da Informação, Malwares, Classificação de Dados, Criptografia, Recuperação de Desastres e Plano de Continuidade de Negócios. O questionário foi encaminhado para as coordenações de curso cadastradas no eMEC, listas de discussão e grupos de profissionais da área de tecnologia em redes sociais.

3. Por último, após a tabulação dos dados obtidos, buscou-se relacionar o resultado do questionário com a carga horária dos cursos encontrados e analisar se o desempenho dos avaliados está diretamente relacionado à disponibilidade de matérias sobre SSI nas grades regionais.

\footnotetext{
${ }^{1}$ https: //forms.gle/2EZjAKo 7VteVURSv5
} 


\section{Resultados}

Foram encontrados 707 cursos bacharelados de SI no portal e-MEC. Dos quais, 202 não possuíam grades de matérias disponíveis no site da universidade, restando 505 cursos. Das grades curriculares analisadas, 92,47\% ofereciam alguma matéria obrigatória, $1.39 \%$ ofereciam alguma matéria optativa e $6,14 \%$ não ofereciam matérias relacionadas a SSI, conforme figura 1(a).

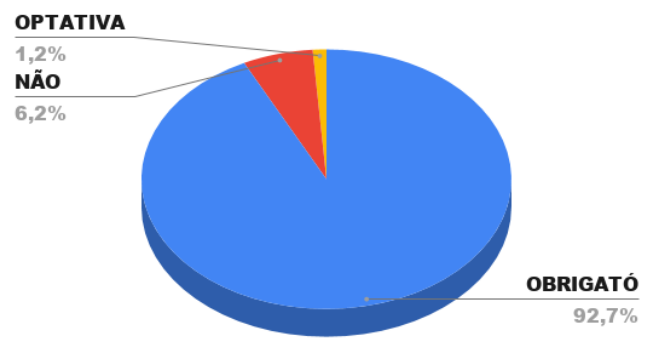

(a) Oferta

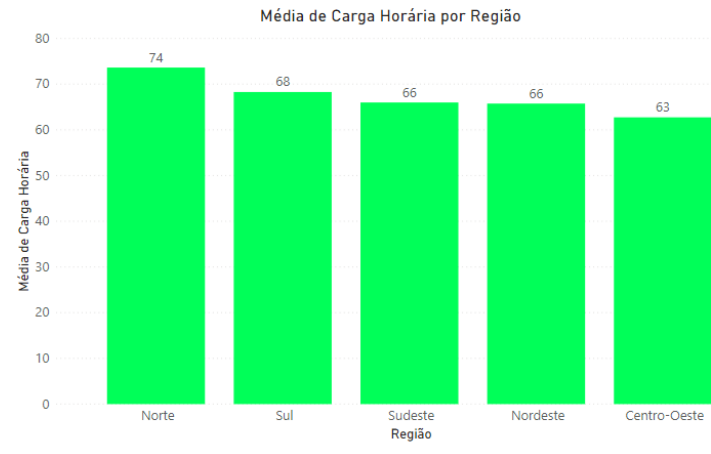

(b) Carga Horária

Figura 1. Oferta X Carga Horária

Posteriormente, comparou-se a carga horária média das disciplinas obrigatórias relacionadas a SSI, por região. A região Norte tem em média 74 horas-aula; seguida pela região Sul com 68 horas-aula; as regiões Sudeste e Nordeste tem em média 66 horas-aula; por fim a região Centro-Oeste com média de 63 horas-aula, conforme figura 1(b).

Foram recebidas 66 respostas ao questionário confeccionado. O questionário possuía 10 perguntas e a média de respostas corretas por região, conforme figura 2 foi de: Sul 6,83 ; Nordeste 6,08; Norte 6,00; Sudeste 5,86 e Centro-Oeste 5,56.

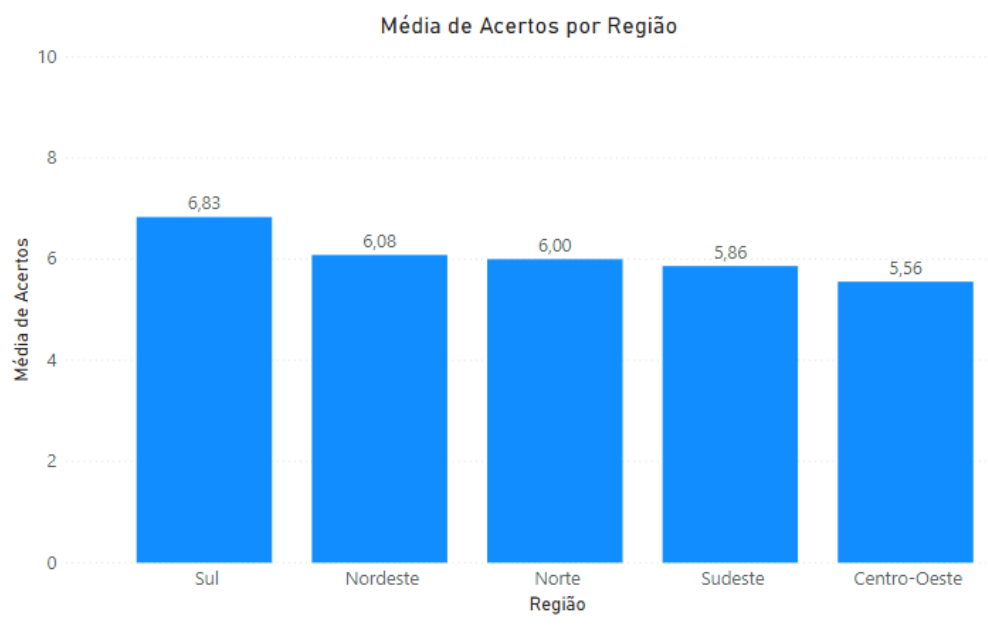

Figura 2. Média Respostas corretas

Vale ressaltar que os participantes erraram algumas questões com mais frequência: Plano de Continuidade de Negócio 83\% de erro; Classificação de Dados 74\% de erro; e Assinatura Digital 59\% de erro. 


\section{Conclusão}

Este trabalho apresentou uma pesquisa sobre a carga horária destinada a disciplinas ligas a segurança em cursos de Sistemas de Informação no Brasil. Os resultados demonstraram que a carga horária oferecida em cada região não está diretamente relacionada ao desempenho dos participantes que responderam ao questionário. Isso pode indicar que a ênfase do conteúdo das disciplinas relacionadas a SSI pode não estar atendendo ao perfil do Bacharel em Sistemas de Informação. Visto que, segundo o Conselho Nacional de Educação (Resolução n⿳5 5, 16/11/2016), uma das atribuições do egresso é "gerenciar, manter e garantir a segurança dos sistemas de informação e da infraestrutura de Tecnologia da Informação de uma organização”.

É importante salientar que menos de um terço dos participantes sabiam quais eram os critérios da Classificação de Dados ou os elementos que constituem um Plano de Continuidade de Negócios; E menos da metade conhecem as garantias oferecidas por uma Assinatura Digital. Ademais, diante da aprovação da LGPD o egresso deverá estar apto a gerenciar atividades de tratamento de dados pessoais e observar os princípios de segurança, através da utilização de medidas técnicas e administrativas para proteção de dados.

Para trabalhos futuros, recomendamos uma pesquisa mais aprofundada sobre o conteúdo programático das disciplinas ligadas à segurança e o perfil esperado do egresso de BSI. E uma relação com as novas demandas da LGPD.

\section{Referências}

Albuquerque, J. P. d., Prado, E. P., Coelho, F. S., and Celso, R. P. (2014). Educação em sistemas de informação no brasil: uma análise da abordagem curricular em instituições de ensino superior brasileiras. Revista Brasileira de Informática na Educação, 22(1):7992.

BRASIL (2018). Lei $\mathrm{n}^{\mathrm{0}}$ 13.709, de 14 de Agosto de 2018. Lei Geral de Proteção de Dados Pessoais (LGPD). http: //www.planalto.gov.br/ccivil_03/ _ato2015-2018/2018/lei/L13709.htm.

Costa, P. V., Gonçalves, W. I., Gonçalves, E. D., and Lazarin, N. M. (2018). Nível de conhecimento de desenvolvedores sobre segurança em aplicações web: Pesquisa e análise. In Anais da V Escola Regional de Sistemas de Informação do Rio de Janeiro, pages 92-99, Porto Alegre, RS, Brasil. SBC.

Marr, B. (2018). how much data do we create every day? the mind-blowing stats everyone should read. Forbes, May 21st. https://bit.1y/2WQyzxK.

Morris, R. and Thompson, K. (1979). Password security: A case history. Communications of the ACM, 22(11):594-597.

Symantec Corporation (2017). 2017 Norton Cyber Security Insights Report - Global Results. https://www. symantec.com/content/dam/symantec/docs/ about/2017-ncsir-global-results-en.pdf. 